\title{
LETTER TO THE EDITOR \\ The good, the bad and the ugly of catheterization practice among elite athletes with spinal cord injury
}

\author{
Spinal Cord (2015) 53, 712; doi:10.1038/sc.2015.56; published online 7 April 2015
}

We read with great interest the recently published paper by Krassioukow et al. ${ }^{1}$ on bladder management-namely, catheterization practice-among athletes with spinal cord injury. In their paper they evaluated athletes participating in paralympic games who performed clean intermittent catheterization (CIC), focusing on urinary tract infections (UTIs) and catheter reuse, demonstrating a higher incidence of UTI in individuals who reused catheters. Furthermore, they evaluated the relationship between country of residence and catheter reuse, showing a significant relationship (higher frequency of reuse and of UTI in developing nations).

In 2012, in the year of the London Paralympic Games, we involved a group of worldwide experts (Center of Physical Reabilitation, Spinal Unit, Pediatric Urology Department) to understand, by their daily experience, $\mathrm{CIC}$ concerns in pediatric and young adult populations. ${ }^{2}$

We used a nine multiple choice questionnaire to define the situation in Italy, Korea, China, Poland, UAE, Taiwan, India, South Africa, the Netherlands, Argentina, Russia, the USA, Vietnam and Thailand, evaluating in this way different clinical scenarios related to diverse social, economic and cultural situations.

In our survey, CIC was found to be recommended worldwide and to be performed in all countries, with the lowest rate in China (15\%); a high percentage of suprapubic and indwelling catheters were also seen in many countries. For CIC, the hydrophilic catheter was found to be the most used (in 12 countries), followed by the gel-coated catheter, nelaton catheter and rubber catheter (used in 4 countries). With regard to catheter reuse it was interesting to note that no reuse was reported by $100 \%$ of participants in only one country, the Netherlands, with a global proportion of $42 \%$ of single use worldwide. In 9 countries there was a common practice of catheter reuse at the rate of one per day, in 5 countries at the rate of one per week and in 4 countries at the rate of one per month. There was no consensus on how to clean a reused catheter (boiling water, 40\%; home-made sodium hypochlorite solution, $20 \%$; milton solution, $13 \%$ and so on). UTI was the most commonly reported complication and was generally related to catheter reuse, but there were too many differences in definitions, preventive measures and treatment methods as reported ${ }^{3}$ and thus it was impossible to provide definitive statistics. With regard to concerns limiting CIC, $47 \%$ indicated economic reasons, $40 \%$ indicated difficulty in obtaining catheters and a high percentage (60\%) cited educational problems. With regard to ways to increase CIC practice, suggestions were related either to economic aspects (catheter cost, reimbursement by Health system/insurance companies), to the need to increase educational programs for patients, families, nurses and pediatricians, increasing the number of health-care providers and providing training programs. It was interesting and surprising to note that our survey results were very similar to the conclusions drawn by
Krassioukov and colleagues, who have considered in their study a selected, elite population, either from the point of view of physical aspects or from a socioeconomic point of view, which was different from the general population of our survey. In our opinion, in their selected population it is difficult to attribute catheter reuse mainly to economic factors and this reinforces our belief in the need to increase health education in developing areas as well as encourage future research on UTI prevention. We totally agree on the role of scientific societies such as International Spinal Cord Society, American Spinal Injury Association and International Continence Society and International Children Continence Society in reducing catheter reuse and UTI frequency, and a common action plan among all societies is desirable.

\section{CONFLICT OF INTEREST}

The authors declare no conflict of interest.

\section{ACKNOWLEDGEMENTS}

We would like to thank all colleagues that participated with us to our data survey: Eun Kyoung Choi, South Korea; Jian Guo Wen, China; Michal Maternik, Poland; Mario Patricolo, EAU; Sthephen S Yang, Taywan; Sujit Chowdhary, India; Peter Nourse, South Africa; Tom De Jong, Netherlands; Miguel Podesta, Argentina; Natalia Guseva, Russia; Lawrence C Vogel, USA; Eric Weerts, Vietnam; Apichana Govinda, Thailand and to Diana Rostrup Nielsen, Denmark; Rikke Vaabengaard, Denmark for their help in data collection.

G Mosiello $^{1,3}$, I Jansen ${ }^{2}$ and M De Gennaro ${ }^{1,4}$ ${ }^{1}$ Department of Nephro-Urology, Neuro-Urology Unit, Bambino Gesù Pediatric Hospital, Rome, Italy and ${ }^{2}$ Medical Faculty, University of Amsterdam, Amsterdam, The Netherlands

${ }^{3}$ Chair of the Children and Young Adults Committee of International Continence Society;

${ }^{4}$ Chairman of the Educational Committee of International Children Continence Society

E-mail: mosiello@opbg.net

1 Krassioukov A, Cragg JJ, West C, Krassioukov-Enns D. The good, the bad and the ugly of catheterization practice among elite athlets with spinal cord injury: a global perspective. Spinal Cord 2015; 53: 78-82.

2 Mosiello G, Jansen I, Rostrup-Nielsen D, Vaabengaard R, De Gennaro M. Clean intermittent catheterization and neurogenic bladder in children and young adults, a short worldwide survey. Abstract Book of 24th Congress of European Society of Pediatric Urology 2013; 57.

3 Wyndaele JJ, Brauner A, Geerlings SE, Bela K, Peter T, Bjerklund-Johanson TE. Clean intermittent catheterization and urinary tract infection: review and guide for future research. BJU Int 2012; 110: 910-917. 